\title{
Article \\ Evaluation of Praziquantel Efficacy against Zeuxapta seriolae Infections in Greater Amberjack, Seriola dumerili
}

\author{
George Rigos*, Dimitra Kogiannou, Antigoni Vasilaki and Mado Kotsiri \\ Institute of Marine Biology, Biotechnology and Aquaculture, Hellenic Centre for Marine Research, \\ 46.7 Athens-Sounio Ave, Anavyssos, 19013 Attiki, Greece; dkogiannou@hcmr.gr (D.K.); avasilaki@hcmr.gr (A.V.); \\ mkotsiri@hcmr.gr (M.K.) \\ * Correspondence: grigos@hcmr.gr; Tel.: +30-2291076494
}

Citation: Rigos, G.; Kogiannou, D.; Vasilaki, A.; Kotsiri, M. Evaluation of Praziquantel Efficacy against

Zeuxapta seriolae Infections in Greater Amberjack, Seriola dumerili. Appl. Sci. 2021, 11, 4656. https://doi.org/ 10.3390/app11104656

Academic Editor: Natalija

Topić Popović

Received: 23 April 2021

Accepted: 18 May 2021

Published: 19 May 2021

Publisher's Note: MDPI stays neutral with regard to jurisdictional claims in published maps and institutional affiliations.

Copyright: (c) 2021 by the authors. Licensee MDPI, Basel, Switzerland. This article is an open access article distributed under the terms and conditions of the Creative Commons Attribution (CC BY) license (https:// creativecommons.org/licenses/by/ $4.0 /)$.
Abstract: The aim of this study was to evaluate the efficacy of dietary praziquantel (PZQ), a promising fish anthelminthic, against Zeuxapta seriolae, a lethal ectoparasite of greater amberjack (Seriola dumerili Risso) farmed in the Mediterranean and elsewhere. The trial was carried out in small cages $\left(3 \mathrm{~m}^{3}\right)$ in situ, harbouring fish $(125 \pm 14 \mathrm{~g})$ naturally infected with $\mathrm{Z}$. seriolae, at $25 \pm 1^{\circ} \mathrm{C}$ water temperature. Praziquantel-medicated diet (150 mg PZQ/ kg fish) was delivered for three days against a control group. Measurement of both adults and oncomiracidia of $Z$. seriolae in sampled gill arches revealed significant differences between the tested groups (PZQ: $19.3 \pm 9.8$ vs. Control: $3.8 \pm 6.3$ ). Considering an estimated efficacy of $80.4 \%$ in the medicated fish, the present study indicates that oral PZQ treatments can confront $Z$. seriolae infections considerably in farmed greater amberjack and, perhaps, replace the commonly used hydrogen peroxidase baths.

Keywords: greater amberjack; ectoparasites; Zeuxapta seriolae; praziquantel; platyhelminths; treatment

\section{Introduction}

Greater amberjack (Seriola dumerili) is a very successful fish candidate for aquaculture due to its attractive growth characteristics and high market prices [1,2]. Farming of greater amberjack has gained global interest and is considered as one of the most important species for diversification of marine finfish production in the Mediterranean area [3]. Among various bottlenecks, disease outbreaks have become a significant limiting factor for the further expansion of greater amberjack farming, both in the Mediterranean region and elsewhere [4]. Zeuxapta seriolae, a gill monogenean parasite, is considered one of the most devastating pathogens in caged greater amberjack [4]. The parasite causes heavy infestations mainly at high water temperatures, which have been associated with anaemia and severe losses in farmed greater amberjack $[5,6]$.

Hydrogen peroxide baths (75-100 ppm for up to an hour) have been proved sufficient to confront Z. seriolae [7]; however, an effective dietary medicine would be an ideal measure to overcome the drawbacks associated with bath applications in large cages, including time-consuming and labor-intensive processes that are stressful and occasionally toxic to fish and dependent on weather conditions.

Praziquantel (PZQ) is a synthetic drug that has been used in human [8], and veterinary medicine and is considered an ideal antiparasitic compound against fish platyhelminths [9]. Its anthelmintic action leads to disruption of the parasitic integument and induction of spastic muscular paralysis [10]. To date, however, PZQ lacks full registration in aquaculture practices, though potential selection of such compounds is possible in aquaculture under the 'off-label' cascade (Council Directive 90/676/EEC, Directive 2001/82/EC and Commission Regulation 37/2010). For those cases, a standard withdrawal time of 500-degree days is enforced to secure consumer safety, considering that a zero maximum residue level has been established for livestock, where the use of PZQ is permitted [11]. 
A comprehensive review on the use of PZQ against platyhelminth fish parasites has been published [9]. Praziquantel given at different dosing schedules, seemed a very effective anthelmintic of farmed fish species [12-14]. The pharmacokinetics of dietary PZQ in farmed greater amberjack have been recently determined with attractive absorption properties [15], however, its PZQ efficacy against fish monogeneans is missing in the Mediterranean region. Consequently, to acquire a complete picture on the anthelmintic value of the drug, the aim of this study was to evaluate the efficacy of dietary PZQ in Z. seriolae-infected greater amberjack.

\section{Materials and Methods}

\subsection{Experimental Set Up}

The trial was carried out in a commercial farming unit, Attiki, Greece. Three hundred juvenile greater amberjack weighting $125 \pm 14 \mathrm{~g}$ and naturally infected with Z $\mathrm{Z}$. seriolae, were transferred from an adjacent cage into six experimental cages $\left(3 \mathrm{~m}^{3}\right)$, aiming to obtain equal biomass (50 fish per cage) (Figure 1).

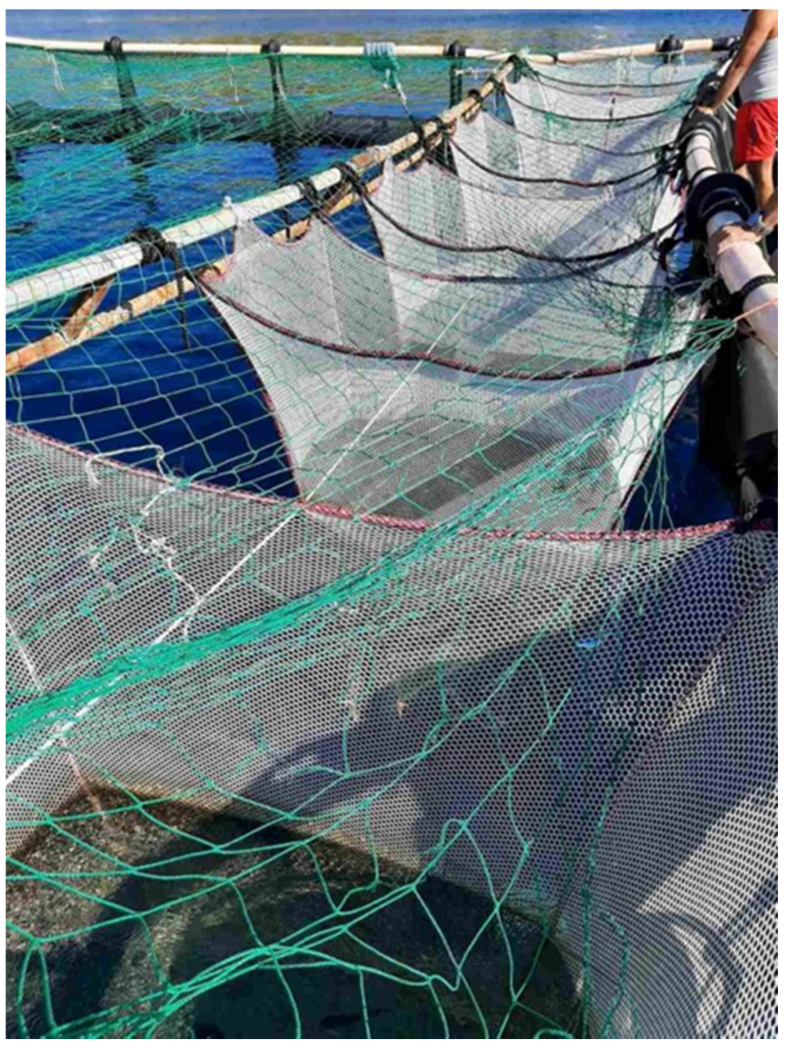

Figure 1. Experimental cages used for the evaluation of praziquantel (PZQ) efficacy.

Three cages served for the PZQ-treated group, while the remainder were used for the Control. The water temperature during the trial was $24 \pm 2{ }^{\circ} \mathrm{C}$. Before the trial, fish were acclimatized to their new environment for two weeks. During that period, fish were fed twice daily at $2 \%$ body weight (BW)/day with the Control diet described in Table 1 . The total parasitic load (both adults and oncomiracidia in all gill arches) of 20 fish from the initial population was examined to ensure the infection with Z. seriolae. 
Table 1. Composition (\%) of the experimental diets.

\begin{tabular}{ccc}
\hline Ingredient $\mathbf{( g / 1 0 0 ~ g ) ~}$ & Control & Medicated Diet \\
\hline Fish meal & 60.00 & 60.00 \\
Krill meal & 12.00 & 12.00 \\
Wheat meal & 18.25 & 17.50 \\
Wheat gluten & 3.00 & 3.00 \\
Fish oil & 5.00 & 5.00 \\
Vitamins & 0.25 & 0.25 \\
Shrimp-based attractant & 1.50 & 1.50 \\
Praziquantel & 0 & 0.75 \\
\hline Proximate composition (\%) & & \\
\hline Moisture & & 7.31 \\
Protein & & 51.68 \\
Fat & & 14.72 \\
Ash & & 8.793 \\
NFEs & & 17.50 \\
\hline
\end{tabular}

${ }^{1}$ Nitrogen free extract.

\subsection{Ethical Statement}

Use of experimental animals in the trial complied with the European Union (EU) directive "on the protection of animals used for scientific purposes" according to the EC Council Directive 2010/63/EU [16].

\subsection{Experimental Feeds}

Fish received two experimental diets (Control vs. PZQ medicated diet; Bayer Ltd., Leverkusen, Germany) of which the composition is provided in Table 1. A sufficient portion of krill meal was included in the medicated diet to enhance acceptability of the medicated diet [15]. The medicated diet was prepared by mixing PZQ $(7.5 \mathrm{~g} / \mathrm{kg}$ feed) with all the feed ingredients prior to pelleting procedure in the pellet mill (Hobart, Arlington, TX, USA). The same process was used for the Control with the exclusion of PZQ. Feeding with the experimental diets was performed twice per day (09.00 and 14.00) for three days at $2 \% \mathrm{BW} /$ day. The daily dosage of PZQ was determined to be $150 \mathrm{mg} / \mathrm{kg}$ fish, considering the feed levels and rates. To ensure acceptance of the experimental diets, fish were monitored for $30 \mathrm{~min}$ after the feeding termination.

\subsection{Sampling for Parasitic Load}

Two days after the completion of the therapy, 10 fish from each experimental cage were screened for the presence of $Z$. seriolae. Fish were anaesthetized with clove oil $(40 \mathrm{ppm})$ and then killed by a blow on the head before taking tissue samples. All gill arches from sampled fish were placed in Petri dishes, rinsed with marine water and examined under a SZ61 Olympus stereoscope (Olympus, PA, USA). Parasitic count included total measurement of adults and oncomiracidia from each gill arch. The efficacy (\%) of PZQ against Z. seriolae in greater amberjack was assessed as previously suggested for parasites [17]:

$\%$ Efficacy $=100-[100 *($ mean number of parasites in PZQ-treated group)/(mean number of parasites in control group) $]$

\subsection{Statistics}

The difference in parasitic load between untreated and PZQ-treated groups was evaluated by using the non-parametric one-tail Kolmogorov-Smirnov test, with the level of significance set at 0.05. Data were plotted in a SPSS program (International Business Machines Corporation, Armonk, NY, USA) for statistical analyses. 


\section{Results and Discussion}

The present study describes the first attempt to evaluate the efficacy of PZQ against $Z$. seriolae in Mediterranean greater amberjack, inspired by the fact that the drug has been a promising parasiticide to confront helminths of Seriola spp. [9] in field and experimental studies. Our trial was carried out with the use of small cages installed in situ and harboring naturally infected fish. This infection model proved ideal for the purpose of the study, where the use of commercial cages as replicates was not economically feasible. Such an experimental set up lacks any technical complexities and can be easily adopted in forthcoming studies using different combination of fish species and ectoparasites.

Acceptance of the medicated diet by experimental fish is one of the main challenges of any PZQ trial. Low inappetence signs were observed herein, which did not affect the overall consumption of the medicated diet. The inclusion of dietary attractants, such as krill meal, was perhaps beneficial to overcome the bitterness of PZQ, as recently demonstrated [15], although previous masking attempts to feed dietary PZQ treatments to various farmed fish species revealed mixed results [12,18-20].

Prior to the study, the total parasitic load from sampled fish was measured to be $21 \pm 6.4$ parasites that was considered acceptable for the initiation of the medication. No mortalities of greater amberjack were noticed during the trial, although the environmental temperature was ideal for the development of the disease and the age of fish used is considered the most susceptible to $Z$. seriolae, possibly due to the acquired protection of older stages, as seen against other pathogens of Seriola [21]. Prevalence of Z. seriolae on the other hand was $100 \%$ in all examined fish. Although PZQ administration failed to fully eliminate Z. seriolae from the medicated group, there were significant differences $(p=0.001)$ in parasitic load between PZQ-treated and Control greater amberjack (Table 2). Moreover, the estimated efficacy in the medicated fish reached a remarkable value exceeding $80 \%$, approaching thus, the corresponding values (81-100\%) calculated in previous studies where PZQ was dietary delivered to fight monogeneans of other farmed fish species [14,22-24].

Table 2. Number of Z. seriolae (adults and oncomiracidia) infecting greater amberjack pre- and post-treatment and efficacy (\%) of in feed-administrated PZQ at $150 \mathrm{mg}$ PZQ/kg for three consecutive days. Data represent mean \pm st. dev. ( $\mathrm{n}=30$ ).

\begin{tabular}{cccccc}
\hline \multirow{2}{*}{ Parasite } & \multicolumn{3}{c}{ Total Number of Parasites } & \multirow{2}{*}{ Efficacy (\%) } & $\boldsymbol{p}$ Value \\
\cline { 2 - 4 } & Pre-Treatment & Control Group & PZQ-Treated Group & & \\
\hline Zeuxapta seriolae & $21 \pm 6.4$ & $19.3 \pm 9.8$ & $3.8 \pm 6.3$ & 80.4 & 0.001 \\
\hline
\end{tabular}

Dietary PZQ treatments have been previously evaluated in other monogenean-infected Seriola spp. For example, the delivery of PZQ at $50-150 \mathrm{mg} / \mathrm{kg}$ fish for 3-6 days against Benedenia seriolae and Z. seriolae infections in yellowtail kingfish (S. lalandi) [14] revealed that lower daily doses of PZQ were associated with fewer parasites compared with fish fed higher daily doses for fewer days. This was attributed to the increased palatability issues emerging from the surface-coating of higher PZQ dosages. Dietary administration of PZQ was promising against Neobenedenia girellae infection in spotted halibut (Verasper variegatus), where a long-term, low-dose treatment $(40 \mathrm{mg} / \mathrm{kg}$ for 11 days) was the most effective measure [12]. Using intubation of PZQ [22], a dosing of 70-120 $\mathrm{mg} / \mathrm{kg}$ for 3 days was very effective against $Z$. seriolae in yellowtail kingfish, while $B$. seriolae appeared more resistant to the drug, necessitating a timed repeat therapy. Full efficacy of PZQ was observed against Heterobothrium okamoti affecting tiger puffer (Takifugu rubripes) when $40 \mathrm{mg} / \mathrm{kg}$ were delivered for 20 days [23].

Sadly, antiparasitic use of PZQ in fresh water farmed fish suffering from helminths, has been mainly evaluated via baths or dips (reviewed by Bader et al. [9]) thereby rendering weak any further comparisons with dietary PZQ applications in other environments.

Comparably, baths with formalin, a widely used therapeutic application for various ectoparasites, seems ineffective against $Z$. seriolae [13], as opposed to hydrogen peroxide baths. The latter can be remarkably effective [7] since in most cases single applications 
are able to completely remove all parasitic stages for a period of a few weeks (Rigos et al., field observations). However, infected greater amberjack has already affected gills due to hyperplasia of the gill epithelium with fusion of the gill lamellae and extreme mucus excretion along with diminished haematological condition [5]. Repeated hydrogen peroxidase baths can further deteriorate gill health of the treated fish, especially if applied with limited caution. Application of baths in caged fish is additionally facing more challenges. Such processes are costly and labor-intensive, weather-dependent and occasionally toxic to fish and the environment. Aquaculture medicine, therefore, should be shifted towards dietary-administered antimicrobials which overcome the above issues. Dietary PZQ can be thus an ideal alternative measure against ectoparasites affecting greater amberjack and perhaps other farmed fish species. This will be extremely important for fish therapy considering that one of the main limitations to combating fish parasites in aquaculture is the scarcity of labelled antiparasitic compounds.

\section{Conclusions}

In conclusion, the findings of this study confirm that dietary PZQ is an effective strategy against helminths of farmed Seriola spp. In particular, oral PZQ treatment of $150 \mathrm{mg} / \mathrm{kg}$ fish for three days can considerably reduce Z. seriolae in greater amberjack and, thus, efficiently replace the commonly used but time- and labour-consuming hydrogen peroxidase baths. Future attempts should concentrate on testing different PZQ dosing schedules. For example, whether an enhanced PZQ treatment schedule combining two dosing periods is more effective than single treatments against $Z$. seriolae infections in greater amberjack remains to be elucidated in following trials.

Author Contributions: G.R.: conceptualization, supervision; D.K.: writing, review and editing, formal analysis; A.V.: methodology; M.K.: data curation. All authors have read and agreed to the published version of the manuscript.

Funding: The research was co-funded by Greece and the European Union under the Fisheries and Maritime Operational Program 2014-2020 (75\% EMFF contribution, 25\% National Contribution).

Institutional Review Board Statement: Validated code of HCMR, EL 25BIO 37. Management of experimental fish followed EC Council Directive 2010/63/ EU. The study was conducted according to the guidelines of the Declaration of Helsinki.

Informed Consent Statement: Not applicable.

Data Availability Statement: Not applicable.

Conflicts of Interest: The authors declare no conflict of interest.

\section{References}

1. Mazzola, A.; Favaloro, E.; Sarà, G. Cultivation of the Mediterranean amberjack, Seriola dumerili (Risso, 1810), in submerged cages in the Western Mediterranean Sea. Aquaculture 2000, 181, 257-268. [CrossRef]

2. Nijssen, E.J.; Reinders, M.J.; Krystallis, A.; Tacken, G. Developing an Internationalization Strategy Using Diffusion Modeling: The Case of Greater Amberjack. Fishes 2019, 4, 12. [CrossRef]

3. Sicuro, B.; Luzzana, U. The State of Seriola spp. Other Than Yellowtail (S. quinqueradiata) Farming in the World. Rev. Fish. Sci. Aquac. 2016, 24, 314-325. [CrossRef]

4. Rigos, G.; Katharios, P.; Kogiannou, D.; Cascarano, C.M. Infectious diseases and treatment solutions of farmed greater amberjack Seriola dumerili with particular emphasis in Mediterranean region. Rev. Aquac. 2020, 13, 301-323. [CrossRef]

5. Grau, A.; Crespo, S.; Pastor, E.; González, P.E.B.; Carbonell, E. High infection by Zeuxapta seriolae (Monogenea: Heteraxinidae) associated with mass mortalities of amberjack Seriola dumerili Risso reared in sea cages in the Balearic Islands (Western Mediterranean). Bull. Eur. Assoc. Fish Pathol. 2003, 23, 139-142.

6. Montero, F.E.; Crespo, S.; Padrós, F.; De la Gándara, F.; Garcia, A.; Raga, J.A. Effects of the gill parasite Zeuxapta seriolae (Monogenea: Heteraxinidae) on the amberjack Seriola dumerili Risso (Teleostei: Carangidae). Aquaculture 2004, 232, 153-163. [CrossRef]

7. Mansell, B.; Powell, M.D.; Ernst, I.; Nowak, B.F. Effects of the gill monogenean Zeuxapta seriolae (Meserve, 1938) and treatment with hydrogen peroxide on pathophysiology of kingfish, Seriola lalandi Valenciennes, 1833. J. Fish Dis. 2005, 28, 253-262. [CrossRef] [PubMed] 
8. WHO. World Health Organization Model List of Essential Medicines (19th List) April 2015; World Health Organization: Geneva, Switzerland, 2019.

9. Bader, C.; Starling, D.E.; Jones, D.E.; Brewer, M.T. Use of praziquantel to control platyhelminth parasites of fish. J. Vet. Pharmacol. Ther. 2018, 42, 139-153. [CrossRef]

10. Staudt, U.; Blaschke, G.; Mehlhorn, H. Light and scanning electron microscopy studies on the effects of the enantiomers of praziquantel and its main metabolite on Schistosoma mansoni in vitro. J. Parasitol. Res. 1992, 78, 392-397. [CrossRef]

11. EMEA. The European Agency for the Evaluation of Medicinal Products. Veterinary Medicines Evaluation Unit. EMEA/MRL/523/98FINAL. Committee for Veterinary Medicinal Products. Praziquantel. Report (2). 1998. Available online: https:/ / www.ema.europa.eu/ en/documents/mrl-report/praziquantel-extension-horses-summary-report-committee-veterinary-medicinal-products_en.pdf (accessed on 23 April 2021).

12. Hirazawa, N.; Mitsuboshi, T.; Hirata, T.; Shirasu, K. Susceptibility of spotted halibut Verasper variegatus (Pleuronectidae) to infection by the monogenean Neobenedenia girellae (Capsalidae) and oral therapy trials using praziquantel. Aquaculture 2004, 238, 83-95. [CrossRef]

13. Sharp, N.; Diggles, B.; Poortenaar, C.; Willis, T. Efficacy of Aqui-S, formalin and praziquantel against the monogeneans, Benedenia seriolae and Zeuxapta seriolae, infecting yellowtail kingfish Seriola lalandi lalandi in New Zealand. Aquaculture 2004, 236, 67-83. [CrossRef]

14. Williams, R.; Ernst, I.; Chambers, C.; Whittington, I. Efficacy of orally administered praziquantel against Zeuxapta seriolae and Benedenia seriolae (Monogenea) in yellowtail kingfish Seriola lalandi. Dis. Aquat. Org. 2007, 77, 199-205. [CrossRef] [PubMed]

15. Kogiannou, D.; Nikoloudaki, C.; Rigos, G. Absorption and depletion of dietary administered praziquantel in greater amberjack, Seriola dumerili. Aquaculture 2021, 535, 736354. [CrossRef]

16. EU. Directive 2010/63/EU. European Parliament and of the Council of the Protection of Animals Used for Scientific Purposes. 2010, pp. 1-47. Available online: https:/ / eur-lex.europa.eu/eli/dir/2010/63/oj. (accessed on 23 April 2021).

17. Stone, J.; Sutherland, I.H.; Sommerville, C.S.; Richards, R.H.; Varma, K.J. The efficacy of emamectin benzoate as an oral treatment of sea lice, Lepeophtheirus salmonis (KrÒyer), infestations in Atlantic salmon, Salmo salar L. J. Fish Dis. 2002, 22, 261-270. [CrossRef]

18. Hirazawa, N.; Akiyama, K.; Umeda, N. Differences in sensitivity to the anthelmintic praziquantel by the skin-parasitic monogeneans Benedenia seriolae and Neobenedenia girellae. Aquaculture 2013, 404-405, 59-64. [CrossRef]

19. Partridge, G.; Michael, R.; Thuillier, L. Praziquantel form, dietary application method and dietary inclusion level affect palatability and efficacy against monogenean parasites in yellowtail kingfish. Dis. Aquat. Org. 2014, 109, 155-163. [CrossRef] [PubMed]

20. Sitjà-Bobadilla, A.; De Felipe, M.C.; Alvarez-Pellitero, P. In vivo and in vitro treatments against Sparicotyle chrysophrii (Monogenea: Microcotylidae) parasitizing the gills of gilthead sea bream (Sparus aurata L.). Aquaculture 2006, 261, 856-864. [CrossRef]

21. Ohno, Y.; Kawano, F.; Hirazawa, N. Susceptibility by amberjack (Seriola dumerili), yellowtail (S. quinqueradiata) and Japanese flounder (Paralichthys olivaceus) to Neobenedenia girellae (Monogenea) infection and their acquired protection. Aquaculture 2008, 274, 30-35. [CrossRef]

22. Forwood, J.; Bubner, E.; Landos, M.; Deveney, M.; Antignana, T. Praziquantel delivery via moist pellets to treat monogenean parasites of yellowtail kingfish Seriola lalandi: Efficacy and feed acceptance. Dis. Aquat. Org. 2016, 121, 201-209. [CrossRef]

23. Hirazawa, N.; Ohtaka, T.; Hata, K. Challenge trials on the anthelmintic effect of drugs and natural agents against the monogenean Heterobothrium okamotoi in the tiger puffer Takifugu rubripes. Aquaculture 2000, 188, 1-13. [CrossRef]

24. Yamamoto, S.; Shirakashi, S.; Morimoto, S.; Ishimaru, K.; Murata, O. Efficacy of oral praziquantel treatment against the skin fluke infection of cultured chub mackerel, Scomber japonicus. Aquaculture 2011, 319, 53-57. [CrossRef] 